\title{
Research on the Ecological Orientation of Digital Public Art and Its Relationship with Urban Development
}

\author{
Suhui Zhang1,** Russell Pensyl 2,a \\ ${ }^{1}$ Shanghai University, Shanghai Academy of Fine Arts, Shanghai 201800 \\ ${ }^{2}$ Department of Art + Design, Northeastern University, Boston, MA, USA \\ ${ }^{a}$ Email: r.pensyl@northeastern.edu \\ *Corresponding author. E-mail: zhangsuhui1520@163.com
}

\begin{abstract}
Against the background of human's universal concern for ecological problems, digital public art also has gained an ecological orientation. Some works have the characteristics of energy conservation and environmental protection, coupled with their intuitive and dynamic images and interactive forms of participation, which can enhance the visual and psychological experience of the audience, and contribute to the expression and acceptance of ecological concepts. Digital public art makes full use of the advantages of digital media technology and artistic creativity to focus the ecological problems on the public vision and cause extensive attention and discussion. The ecological orientation it presents makes it closely connected with the sustainable development of contemporary society and future cities, and at the same time, makes itself obtain a broad development space in the cities.
\end{abstract}

Keywords: Digital, Public art, Ecology, LED art, Solar energy, World Expo.

\section{INTRODUCTION}

In recent years, with the development of digital technology, interactive installation art, LED art have been constantly involved in the vision of public art, which promotes the emergence of a digital trend in public art. These art forms are typically referred to as "digital public art". As is known, an important value public art lies in its concern and discussion of social issues. [1] The digital variant of public art is no exception.

Given the increasing public's concern about ecological issues, many designs, artists and influencers are focusing their work around this topic. The book "International Public Artists' Discourse on Ecology" brings together many Chinese and Western artists' theoretical research and creative practice in this field. Artists carry out ecological discussions in the field of public art from

*Fund source: general art project of National Social Science Foundation of China, "Research on public art and urban future development based on ecological concept from the perspective of ecological civilization" [18bg116]. different perspectives, involving ecological issues such as climate warming, resource recycling, environmental protection, solar energy utilization, and natural concern, providing people with an overall observation perspective. [2]

These types of digital public art have the subject matter characteristics of energy conservation and environmental protection, coupled with the form of intuitive and dynamic images and interactive participation, which can strengthen the visual and psychological experience of the audience, thus contribute to the rhetorical influence and acceptance of the ecological concepts. Some ecological concepts that are deeply rooted in the hearts of the people can be conveyed via the form of digital public art. Expo 2010 Shanghai can be described as an experimental field of digital public art, which can provide people with a perspective of focusing on such public arts. Due to the ecological theme and orientation of Expo 2010 Shanghai, a large proportion of these digital public arts involve sustainable urban development, low-carbon footprint, environmental protection and other 
similar topics. The ecological orientation of digital public art has established a close relationship with the sustainable development of contemporary society and the future city, and may also generate broad acceptance for the development of digital public art.

\section{THE INTERSECTION OF ART AND TECHNOLOGY CREATES AND CONSTRUCTS DIGITAL PUBLIC ART}

The emergence of digital public art is a good response to the discussion on the relationship between art and technology over the last decades. Since mankind entered the information age, the frequency of integration among disciplines has accelerated, and various interdisciplinary and comprehensive disciplines have emerged. Art and technology have converged in unprecedented ways. The involvement of digital technology has changed the way of thinking, creation and existence of art, created the characteristics of multimedia integration of digital public art, made it the product of the convergence of art and technology, and also blurred the boundary between art and technology to a certain extent.

Compared with the singleness of traditional public art creators, digital public art relies on a kind of joint force to gather the creativity, wisdom and professional acumen of artists, designers, software engineers, among others, gather the knowledge and vision of the arts design, digital technologies, and other comprehensive disciplines, and create an effective interactive display model. This breaks with the traditional point-to-point, one-dimensional art viewing and acceptance model. The audience can even participate in the creation of the works together. With the help of the plethora of input methods (mouse, keyboard, touch screens) and various sensor devices, the objects in the virtual environment can be manipulated and controlled, which not only makes the work more attractive and have a prominent role in conveying ideas, but also makes the work more popular because of strengthening the characteristic of public participation.

Digital technology brings unprecedented changes to art making and art consumption. This not only changes the way of thinking and exigency of art at a certain level, but also greatly changes the mode of creation and adoption of new art forms. At the same time, the integration of digital media, realtime interaction and the change of the exhibition form combine art and technology closely together to exert a joint force, and constantly bring more diverse expressive power and profound explanatory power to digital public art.

\section{DIGITAL PUBLIC ART BASED ON ECOLOGICAL CONCEPT IS INCREASING GRADUALLY}

In various urban public spaces, digital public art, based on ecological concepts is increasing gradually. With the intervention of interactive technology, the initiative and enthusiasm of the public in the process of viewing and experiencing digital public art are stimulated and strengthened. In an interactive situation, the transmission of ideas is often more intuitive and effective. Especially for some works with eco themes, such as environmental pollution, global warming, endangered species and so on. These ecological issues become more intuitive, vivid and truly due to multimedia display or real-time interaction, which brings an immersive emotional experience and a stronger sense of urgency to the audience, and then helps to stimulate the public ecological consciousness.

Taking a multimedia interactive installation art of South Korea Pavilion in Expo 2010 Shanghai as an example("Figure 1"), the audience can design marine organisms, such as turtles and various fish through the touch screen. Then they can tap to release it into a virtual ocean environment, and it will swim freely into the deep sea, and can monitor water quality changes. In the process of interactive participation, the audience's spirit is often accompanied by a series of evoked internal emotions. The audience will first experience the excitement of creating marine life by their own, and then generate a sense of concern for them, and further understand the profound meaning of this work, that is, to pay attention to and protect the home where people and animals live together on this planet. This series of emotional experience comes from the interaction with the works. In his book "Persuasive Games", Ian Bogost coined the term procedural rhetoric. The concept combines the concept of procedural process with the concept of rhetorical devices in persuasive speech. Through his work in this area, Bogost demonstrates that using gamification, or game mechanic can be successfully employed to encourage adoption of certain points of view. [3] This technique is effectively leveraged in game like experience and interaction strategies as seen in the Korean 
Pavilion. The computer and multimedia technology create the vivid, interactive, real-time and on-thespot sense of reality for the works, and the digital narrative technique of the works can also evoke association and thoughtfulness within the processes of public participation in the interaction, and imperceptibly realize the transmission and acceptance of the ecological concepts.

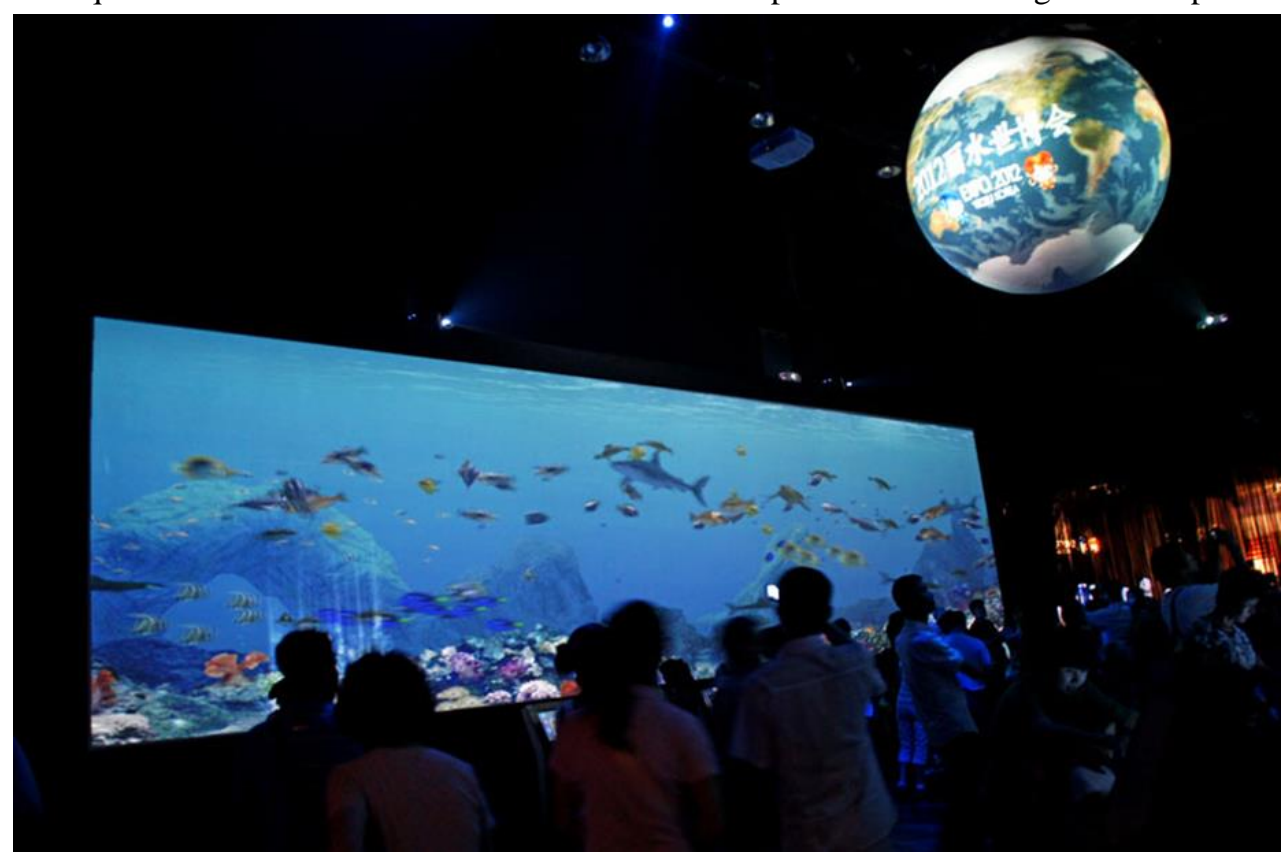

Figure 1 Multimedia Interactive Installation Art of South Korea Pavilion in Expo 2010 Shanghai.

Ecological issue is the core topic of contemporary society, and the attention to ecological issue implies the social connotation of public art. At present, due to the frequent occurrence of ecological issues, as well as the increasingly urgent demand for low-carbon, energy saving and environmental protection all over the world, various fields are exploring how to respond to the this kind of demand. In the field of digital public art, works and activities with the theme of ecology are becoming more and more common. They make full use of the advantages of digital technology and artistic creativity to focus ecological issues on the public perspective and arouse widespread concern and discussion.

\section{ECOLOGICAL ORIENTATION OF INTERACTIVE INSTALLATION ART}

Interactive installation art usually refers to some works that can interact with the public through gestures, actions, sounds, etc., and artistically present the interaction process and results through display screens, lights, etc. In recent years, the influence of interactive installation art in public space has been increasing, which makes it gradually get involved in the vision of public art, and gradually become an important form of digital public art. It is usually displayed in the form of face-to-face communication and interaction. In the process of interaction, the public's role changes from passive viewing to active participation, cocreation, and even become co-evolutionary as active part of the artworks. In addition, the nonlinear narrative features of some works are beneficial to the participation of the public and the understanding of the connotation of the works, so that it becomes an effective carrier for some artists and designers to express their ecological concepts and messaging.

With the help of sound, light, electricity and other medias as well as diversified language modes, interactive installation art often creates rich audiovisual effects and dynamic, changing, interactive characteristics, making it particularly suitable for the expression of energy-saving, environmental protection, green, low-carbon and other ecological themes of general concern around the world in the current era. At the same time, in the process of interaction with the works, the public's sense organs such as sight, hearing and touch can be mobilized, and in the common ground[4] created by interactive installation art, rich associations and immersion experience can be further generated. As some scholars have said, "immersion" is a special 
phenomenon in the human spiritual ecology, characterized by the people's concentration on a certain realm or ideological activities." [5] This kind of activities is usually along with a minor dissociative state or suspension of reality, which have unusual significance for people. As stated by Murray, "Agency and immersion are mutually reinforcing. When we engage with an immersive world and it responds to us as we expect it to, revealing deeper levels of content, greater detail in its coverage, we become more deeply immersed." [6] Immersion is often seen arising from the application of virtual reality technology and some auxiliary devices, such as 3D image, tracking technology, tactile/force feedback, etc., to provide real, natural and real-time human-computer interaction. These characteristics make the interactive installation art particularly suitable for the messaging sustainability of energy conservation, environmental protection, green, low carbon and other social concerns of the ecological theme. Some interactive installation arts interpret the theme in multi-dimensional and visualized way through interactions and non-linear narrative techniques, and through the use of multimedia to mobilize people's multiple senses, and then make people immersed in the virtual environment experience. The adoption of these techniques enables digital public art to intuitively reflect on

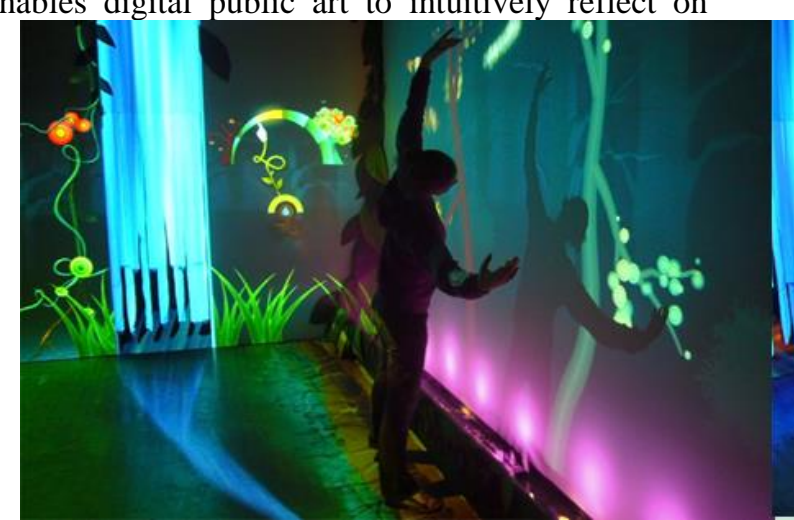

ecological issues and explore ways to realistic solution that can be adopted by the population at large. In the face of such artworks related to the future fate of human beings and the future development of cities, the public's participation and enthusiasm can often be more aroused, so as to produce a certain emotional resonance. Thus it can be seen that interactive installation art has outstanding advantages in expressing ecological concepts. Compared with the simple propaganda, it is more effective to realize the transmission and acceptance of ecological concepts by means of "teaching goes together with pleasure".

Funky forest ("Figure 2"), created by artist Theodore Watson in 2007 in Holland, is an interactive installation art full of ecological orientation. The work presents an interactive virtual ecosystem. The public can influence the virtual ecosystem with body language. They can make trees, and lead the water of the waterfall to trees to supply water, so as to help the creatures in the virtual forest grow and multiply. In the process of interaction with the work, the public has the opportunity to understand the operation mechanism of the ecosystem and participate in the protection of the virtual forest, and stimulate the ecological consciousness of forest protection in the process of an immersive experience.

Figure 2 Theodore Watson: Funky Forest.

Interactive installation art breaks through the boundaries between art and other fields, links rich and diverse expression factors, and enables people to have a sense of immersive experience in the process of viewing works. Through the physical interaction with the works, and the emotional interaction created by the perceptual form and connotation, they can feel and understand the ecological concept contained in the works.

\section{ENERGY SAVING AND ENVIRONMENTAL FRIENDLY LED ART AND ITS COMBINATION WITH RENEWABLE ENERGY}

In recent years, LED art continues to shine in the urban public space. It can not only become an independent lighting installation art, but also be attached to the building, transforming the external facade of the building into a multimedia wall. LED 
itself is a kind of light-emitting diode, which has been used in various display fields. In recent years, it has gradually stepped into the field of digital public art, adding new vitality to the city with its rich and changeable dynamic visual image. Moreover, with its energy-saving and environmental protection characteristics and the attempt to combine with renewable energy, it has expanded the discussion of art in the field of ecology, which is conducive to sustainable urban development in the future.

\subsection{Energy Saving and Environmental Friendly LED Art and Its Characteristics}

The popularity of LED art in the contemporary era stems from the following characteristics: The dynamic and changeable art effect supported by high technology, which integrates computer technology, multimedia technology and network technology, and has the characteristics of online programming and flexibility. LED light source can realize rich changes of patterns and colors under the control of software and can be used to create dynamic and changeable visual art forms; Environmental friendly. These systems emit little electromagnetic radiation or harmful substances; Energy-saving. LED lighting systems use about $70 \%$ less energy than traditional incandescent light sources, which can reduce energy consumption to a large extent. [7] As well, less electricity is needed for the control systems to achieve a variety of visual effects, and meets the ecological needs of low-carbon society and sustainable urban development; Many large scale LED lighting systems use small microcontrollers that draw only 5 to 12 volts for normal operation.

In public spaces around the world, LED art is becoming more and more prevalent. It not only creates a colorful and changeable urban visual landscape, but also attracts more attention by urban populations. The utilization is increasing because of its energy-saving and environmental friendly characteristics. The emergence of LED art is fits within awareness need by the average population about our global ecological crisis and the appeal of low-carbon impact society. At a time when people generally question the consumption of resources and energy in the process of setting up large-scale public art and the negative impact on the environment, the emergence of such an art form is appropriate. Therefore, the public's ecological consciousness has gained a powerful art carrier, and
LED art has been growing rapidly, and has become an important form of digital public art.

The Crown Fountain in Millennium Park, Chicago ("Figure 3") is such a digital public art, which consists of two huge LED lighthouses, one side is LED screen, and the other three sides are equipped with color changing LED lights. The smiling faces of 1000 Chicago citizens are presented in the work at the frequency of 6 per hour. Giant faces pout and smile from time to time. Occasionally, a stream of water sprays out of the mouth. The public often gather around it with great interest and look forward to the moment of water spraying. This is not only a digital public art that can trigger public interactions and games, but also a place to create happiness and meanings. Therefore, the public space becomes more rich and artistic. At night, the work will be transformed into images of natural landscapes such as forests and waterfalls, creating a poetic and natural ecological home, creating a place full of meaning, making it an important city landmark of Chicago, attracting many tourists from all over the world, and producing a wide range of public effects. What's more enlightening is that energy conservation and environmental friendly characteristics of its materials are related to the context of sustainable development of the city, and also provide an artistic thinking for the discussion of ecological issues. 


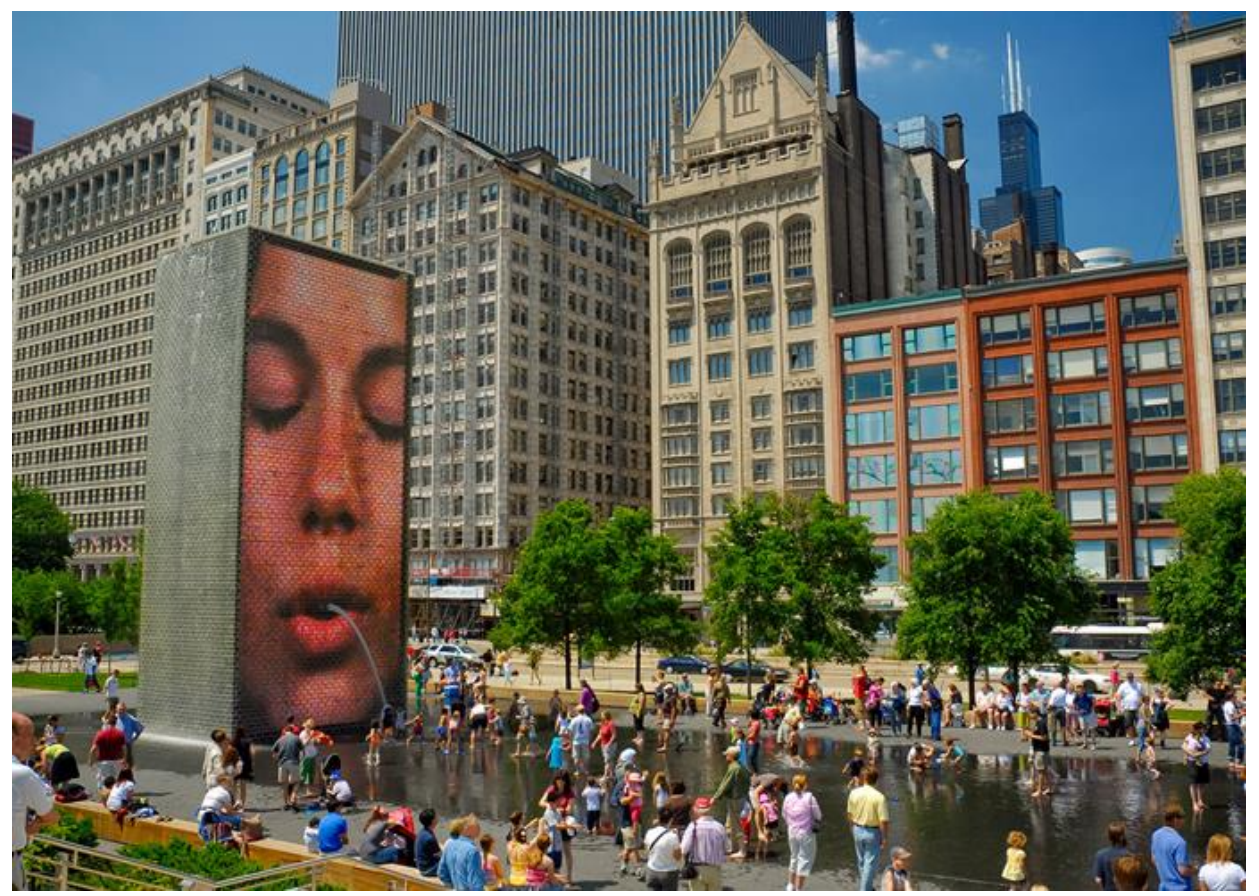

Figure 3 The Crown Fountain in Millennium Park, Chicago.

\subsection{The Meeting of LED Art and Solar Energy}

In the development process of LED art, a new trend is gradually emerging, that is to use solar energy to supply power, in order to reduce the consumption of non renewable energy and realize the self sustainability of works. Therefore, helping LED art that already has energy conservation and environmental protection characteristics gain more ecological attributes and expand more dimensions.
In 2009, LED art Language of the Birds ("Figure 4"), jointly created by Brian Goggin and Dorka Keehn, was commissioned by the San Francisco Art Council and set up on Broadway Street in San Francisco. As part of the urban improvement project, this work is the product of the cooperation between artists and scientist David shearer, integrating the wisdom of technology and the creativity of art.

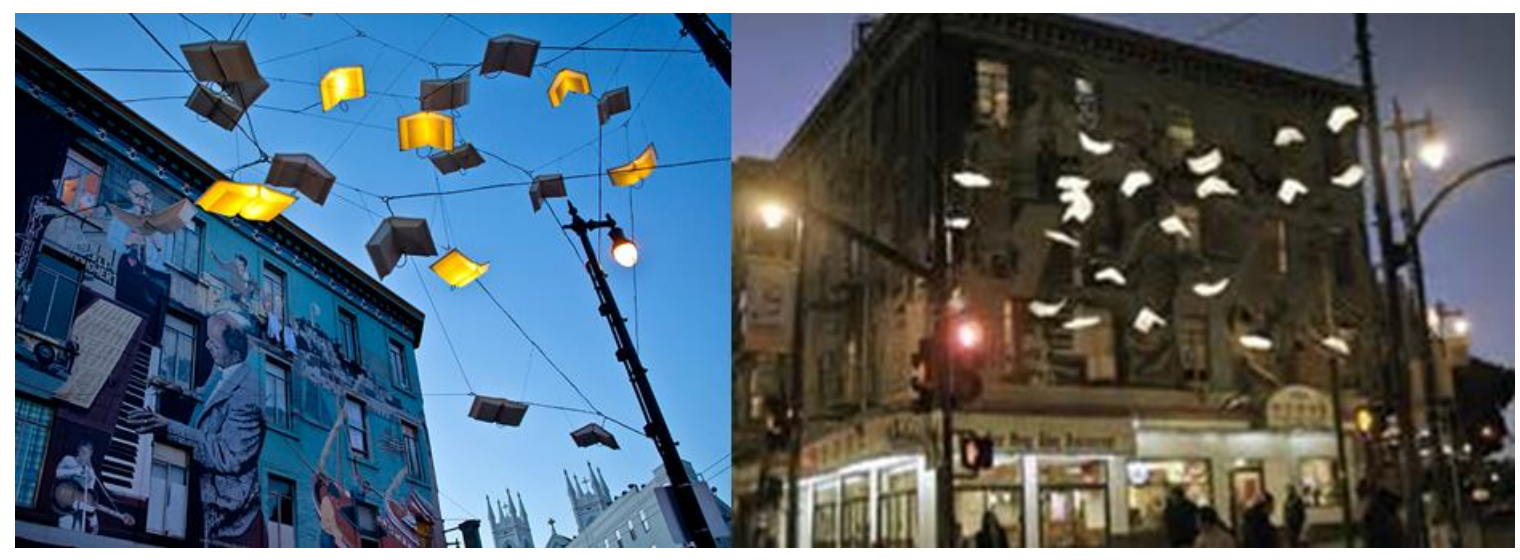

Figure 4 Brian Goggin, Dorka Keehn. Language of the Birds.

Language of the Birds looks like a flock of pigeons fluttering in the distance, and it also looks like flying books. There are words of different countries on the ground directly below, as if they were fallen from the books. In addition to the rich images, Language of the Birds is a digital public art using solar energy, which is composed of 23 solar books suspended on a geometric stainless steel net. During the day, the solar panels at the top of the books constantly absorb the solar energy. At night, 
the LED lights embedded in each book are lit, showing a dynamic and variable scene, sometimes emitting a weak light, while sometimes releasing a gorgeous and spectacular optical effect. The form of the book is a combination of symbolism and function, and the form with artistic appeal has the actual purpose of obtaining energy. The image of the book and the white light of the LED create the intellectual light, lighting up the night sky of the city, and adding the humanistic atmosphere and poetic flavor to the ordinary square in the city. Language of the Birds gained wide public recognition rapidly after its installation, and then became a highly recognized city landmark.

The ecological orientation presented in the digital public art explores a new path for the sustainable development of the city, that is, in the era of energy shortage, more and more urban public arts can self-sustain, so as to reduce the consumption of non-renewable energy.

\subsection{A Dialogue Between LED Art and Wind Energy}

In addition to solar energy, wind power is also gradually stepping into the pace of combining with LED art and entering the public vision. The large

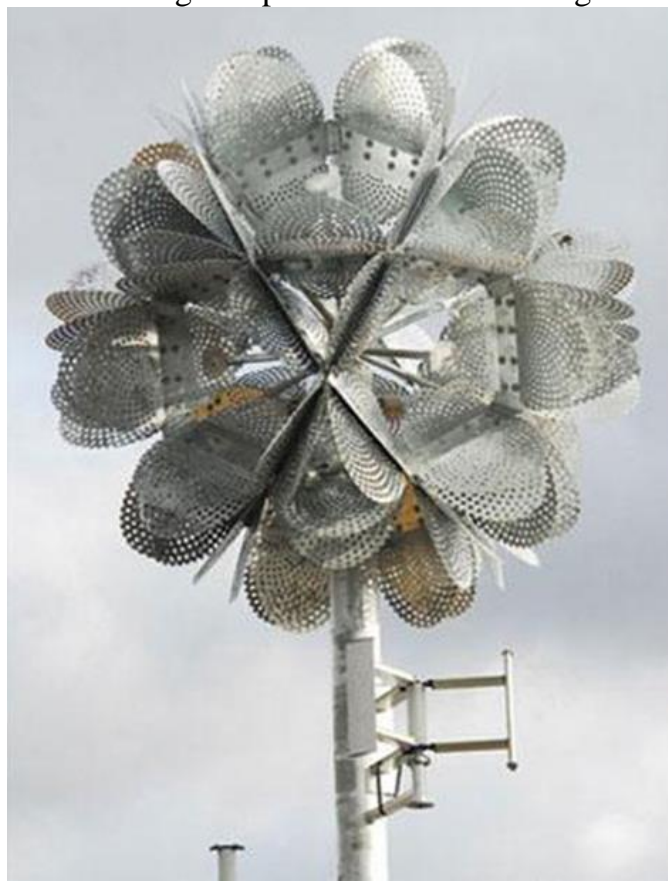

Figure 5 Tonkin Liu Studio. Future Flower.

The use of wind as an easily accessible and renewable energy source in this work has also aroused people's concern and thinking about the extensive use of renewable energy in public art, as sculpture "Future Flower" ("Figure 5") designed by Tonkin Liu studio in London is the wind energy LED art using wind power. The metal flower, which is more than ten meters high, is set beside the Mersey River in the UK as part of a project to revive the old waterfront industrial zone. There are 60 wind turbines built in the artwork, which transform and store the electric energy generated by wind according to the principle of windmill. Meanwhile, each petal is also equipped with LED lights. When the wind speed exceeds $5 \mathrm{mph}$, the lights will gradually increase, forming a red light. The change of wind creates colors of different intensities, and also constructs the dynamic appearance of the work. When there is no wind, the metal petals reflect the changing colors of the sky and the sun, making the work have the attribute of dialogue with nature. The intervention of public art adds artistic atmosphere and landscape quality to the old industrial area, and the integration of the metal materials representing industry and the flowers representing nature also symbolizes the combination of industry and nature. This work carries the ideal of symbiosis among art, science, and ecology, and contains the concept of sustainable development in the renewal of the old industrial zone.

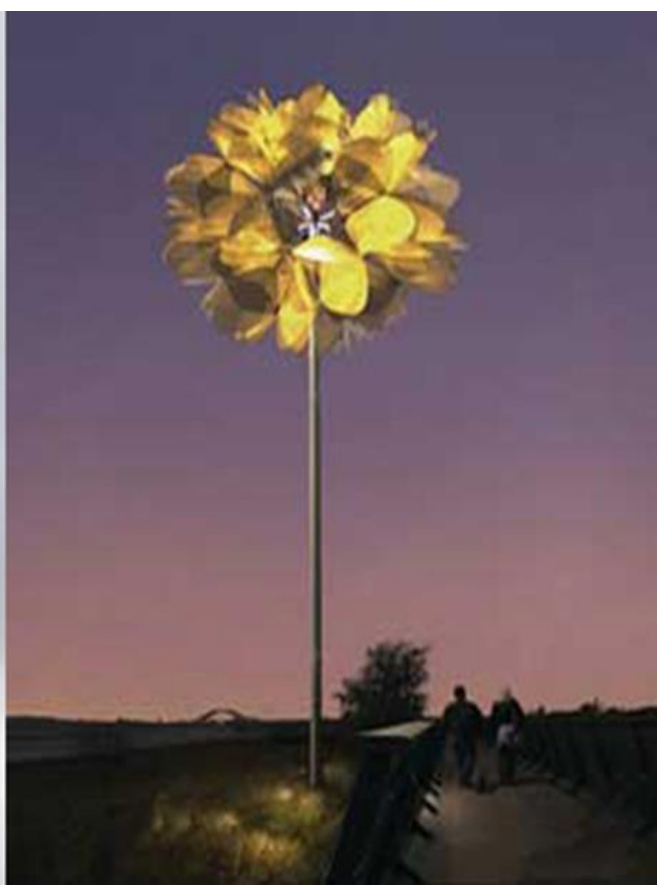

well as the discussion on the relationship between public art and natural elements. Although the use of wind energy to achieve self-sustaining characteristic of works is not common in the field 
of public art, yet people have felt that this form not only has a strong ecological consciousness, but also in line with the pace of urban sustainable development. Like solar energy LED art, wind energy LED art is also based on the ecological concept of energy conservation and environmental protection and achieves the self-sustaining characteristic and the intelligence of dialogue with nature via the computer program. This also opens up a new exploration space for public art and the future development of the city, which is of enlightening significance to artists and designers with ecological consciousness. If we can further expand the public art practice in this field in the future, public art will get a broader development space and better integrate into the sustainable development of the city.

\section{THE ECOLOGICAL ORIENTATION OF DIGITAL PUBLIC ART IN SHANGHAI WORLD EXPO}

Digital public art has become an increasing visual form in the World Expo in recent years. It is not only an important display content and means, but also a digital public art that integrates science and technology with art, gathers ideas and thoughts, includes interaction and participation. Compared with the static plastic arts, it sometimes has more visual expression and attraction, and is more likely to stimulate public participation, so that it can realize the communication and acceptance of ideas during the physical and emotional interaction between the public and the work. The theme of Expo 2010 Shanghai is "ecology". The master plan, exhibition content, architecture and landscape design and landscape support system are all integrated with a strong ecological concept, reflecting the ecological exploration of low-carbon lifestyle, urban ecological harmony, and sustainable development. Although it has been a while since Expo 2010 Shanghai was closed, it still provides people with a perspective to observe this kind of public art as a whole and a model of research in this field and gives people multiple inspirations.

\subsection{The Concept of "Ecological Expo" and the Response of Digital Public Art}

The theme of Expo 2010 Shanghai is "Better City, Better life", which includes the contemporary choice and future mission of urban sustainable development, low-carbon, energy saving and environmental protection of the city. From the perspective of digital public art alone, we can observe a variety of ecological themes and interpretation angles, including the harmonious coexistence of human and nature, ecological warning and reflection, using energy saving and environmentally friendly materials.

Under the advocacy of the concept of "Ecological Expo", the ecological concept of energy conservation and environmental protection was embodied in all aspects of the planning, design, construction, and operation of Expo 2010 Shanghai. The Expo Axis adopted LED lighting art to interpret the concept of "Light, City, Life and Future". At the same time, The Urban Best Practice Area and various venues of the Expo Park also adopted LED lighting art form, which is more than $70 \%$ energy-saving compared with the traditional lighting art. Six trumpet shaped Sunshine Valley of Expo Axis was also a digital public art containing the concept of energy conservation and environmental protection. In addition, there were various kinds of interactive installation art based on ecological concept in various venues. People are often attracted by these dynamic or interactive exhibition contents or artworks. As some scholars have pointed out, "In addition to direct trade, largescale exhibitions are more about the dissemination, promotion, guidance and exchange of new ideas, technologies and knowledge. It faces more nonprofessional audiences. They hope that in addition to getting updated information during the visit, the visit process will be full of fun and novel experience." [8] Expo 2010 Shanghai may be regarded as an experimental field of digital public art. These works annotated the ecological theme from different perspectives, and created a visiting experience with a sense of presence in the form of intuitive and dynamic image and interactive participation of the public, so as to convey the ecological concepts or warn the ecological crisis, put ecological issues on a public platform, and arouse more public reflection and discussion.

\subsection{Artistic Solar Installation: the Ecological Concept of Sunshine Valley}

Solar energy device refers to the device that provides power, hot water, etc. for the site. It can use solar energy to relieve the power pressure of the city, so as to achieve self-sustaining in energy of the site to a certain extent. Compared with a pure functional solar energy device, if it can be endowed with more aesthetics and culture in external form, it will expand its extension, enrich its semantics, and 
have double benefits of function and aesthetics. The artistic solar energy device mentioned here is slightly different from the solar LED art mentioned above. The former focuses more on art, while the latter means solar power generation or the power device with aesthetic meaning.

Sunshine Valley ("Figure 6") of Expo Axis is a work with multiple ecological concepts and artistic appearance. Solar LED intelligent star lights are set on the inner side of petal shape structure, which can use solar energy to supply power for illumination and lighting art during night. The outer node of the work is equipped with LED intelligent star lights, which can not only present colorful lighting effects, but also transform the surface of the work into an LED display screen, and present information such as image, text, video, and so on. It served as an information medium on the Expo Axis during the Expo.

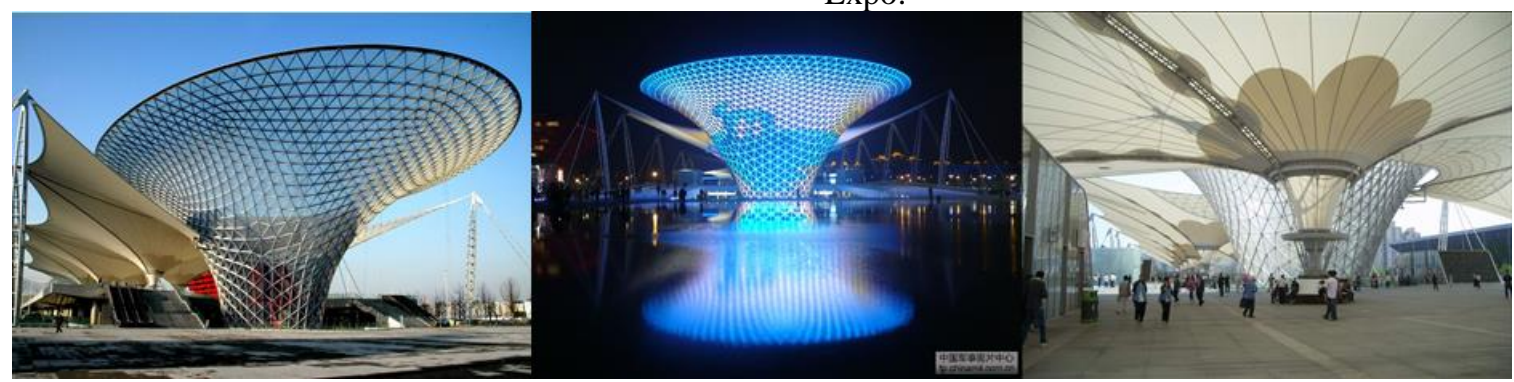

Figure 6 Sunshine Valley of Expo 2010 Shanghai.

The six trumpet shaped Sunshine Valley can fully introduce sunlight and natural air into the underground space of Expo Axis, improve the air quality, reduce the energy consumption caused by artificial lighting, and provide a comfortable and natural environment for the people waiting for the exhibition. Sunshine Valley also has the function of rainwater collection. The recycled and purified rainwater can be used for plant irrigation in the Expo park. Both art and ecology are closely combined in this work, which effectively explains the theme of "Ecological Expo". It also has profound semantic connotation in the external form, symbolizing green and vitality. The solar energy flowers on the Expo Axis reflect the designers' discussion on the theme of "Better City, Better Life" from the perspective of ecological concept.

Many pavilions or art forms in the World Expo are not set up permanently. It is because of this temporary nature that all kinds of experimental buildings and cutting-edge art forms can bloom freely in this soil. In this stage, digital media technology and art continue to integrate and innovate, bringing people a feast of digital public art. From the perspective of public art, Expo 2010 Shanghai can be regarded as a stage of digital public art. This paper further focuses on those works that pay attention to ecological issues, call for energy conservation and environmental protection, and have ecological features in terms of creative ideas and techniques, material selection, etc. Expo 2010 Shanghai just provides us a perspective to focus on such works, so that we can explore the direction of urban sustainable development from the perspective of art.

\section{THINKING ON THE RELATIONSHIP BETWEEN DIGITAL PUBLIC ART BASED ON ECOLOGICAL CONCEPT AND URBAN DEVELOPMENT}

In the field of digital public art, there is an increasing number of activities with the theme of "ecology". One may ask why a considerable number of public artworks are given an ecological theme. It can be seen that there is an increasing awareness of a social orientation of the population and the population's awareness of nature, the urban environments. The artworks evoke consciousness of this awareness. Many artists and designers create with a sense of mission, which makes the number of works reflecting on ecological issues gradually increase. Moreover, some digital public arts themselves have the characteristics of energy conservation and environmental protection. For example, LED art can not only reduce energy consumption to a large extent, but also has highquality artistic effect and stronger plasticity. At the same time, LED art is increasingly combined with solar energy, wind energy and other renewable energy, which makes its energy-saving and environmental protection characteristics multiply. These factors are the important reasons for the generation and development of ecological orientation in digital public art. This orientation 
conforms to the needs of energy conservation, environmental protection, and a low carbon footprint for urban sustainable development. To a certain extent, these digital public arts have established the same breath and common destiny with the future development of the city.

In addition, digital public art itself has employs narrative and intuitive image characteristics, that creates outstanding advantages in the expression and interpretation of ecological themes. Employing these rhetorical devices encourages an emotional response to the approaching of ecological crisis. It has been said that role of design is to change behavior. The use of rhetorical art and design encourages adjustment of behavior, and establishing self-awareness and self-reflection of ecological concerns. The combination of multimedia, interactive participation, immersive experiences, and other characteristics enhance the precious affinity and attraction for the public. Various ways of "Teaching with Pleasure" can subtly realize the transmission and acceptance of ecological concepts, which help to further stimulate the public's ecological consciousness. The future development of the city cannot be separated from the sustainable development of the city, which depends on the establishment of each individual's ecological consciousness.

Digital public art originates from the intervention of new media art. It covers the power of computer technology, multimedia technology, network technology and other comprehensive disciplines. Some scientists, engineers even create digital public art directly, which also changes the identity of public artists from independent creators to co-creators. It is also easier to send out a bright light of wisdom and create more extraordinary works. For the ecological issues that frequently appear in contemporary era, if we can discuss them with the help of multi-disciplinary forces, we will get multi-dimensional intellectual support and diversified solutions.

To sum up, the attention and reflection on ecological issues, the energy conservation and use of environmentally friendly of materials, the utilization of renewable energy, and the energy conservation of public art sustaining system continue to build the ecological nature of digital public art from the form, theme, connotation, materials, techniques and other aspects, etc. Furthermore, the characteristics of its interaction in form, interest in content, refinement in artistic connotation, integration of social common values and so on, make digital public art easier to attract the public, and the form of intuitive and dynamic image and interactive participation are conducive to the warning of ecological problems and the transmission of ecological concepts, which have a positive effect on the sustainable development of city from different levels.

As well, if we hope public art to obtain the power of sustainable development, it needs to share the same fate with the city, which is not only in line with its nature, but also a way to better base on the present and constantly expand space, and also the way to its future development. Only when the construction and development of a city is more based on the consideration of ecological environment and the consideration of the future can it obtain the power of sustainable development. At the same time, public art has been brought into the construction of urban sustainable development. The sustainable development of a city cannot be separated from the harmonious symbiotic environment of human, nature and city, the energysaving, environmental protection and low-carbon lifestyle, and the ecological discussion of all walks of life, relying on the establishment of each individual's ecological consciousness. In these aspects, digital public art has begun to show its advantages. They make comprehensive use of the advantages of digital media technology and artistic creativity to focus the ecological issues on the public vision and cause extensive attention and discussion, so as to have a positive effect on the sustainable development of the city. At the same time, they also continue to expand the space for the development of public art in the city.

\section{CONCLUSION}

The ecological orientation presented in the digital public art makes it establish a close relationship with the sustainable development of the contemporary society and the future city, and meanwhile, it also makes itself obtain a broad development space in the city. As an important form of contemporary public art, digital public art is not only the field of multi-disciplinary integration, but also the field of active exchange of ideas. At the edge of interdisciplinary, there are often some bright spots. The ecological orientation of digital public art can be summed up in two points, that is, the ecological nature of the concept and the ecological nature of the means. The former, such as LED art, its ecological orientation is due to the nature of the material itself and ecological 
discussions, while other types of digital public art also have works that warn and reflect on ecological issues. These works annotate the theme of ecology from different perspectives. In the form of intuitive and dynamic images and interactive participation, they create a visit experience with a sense of presence, convey the ecological concept or warn the ecological crisis, place the ecological issues on a public platform, and cause people to think and discuss more, and build self-consciousness and selfreflection of ecological issues.

\section{AUTHORS' CONTRIBUTIONS}

Suhui Zhang wrote the manuscript, and Russell Pensyl contributed to revising and editing.

\section{REFERENCES}

[1] Knight, Cher Krause (2008). Public Art: theory, practice and populism. Oxford: Blackwell Publishing. ISBN 978-1-40515559-5.

[2] Edited by Yang guini. International Public Artists's Discourse on Ecology, Shanghai Literature and Art Press, 2011. ISBN 978-75321-4238-5.

[3] Bogost.I, Persuasive Games, The Expressive Power of Videogames. MIT Press, ISBN: 9780262514880, August 2010.

[4] Cornett. J.A., Kuziemsky. C., A model of collaborative agency and common ground, Studies in health technology and informatics, February 2013.

[5] Zhang Zhaohui, Xu Ling: New Media Art 2004, People's fine arts publishing house, 2004, P22.

[6] Murray, J.H., Inventing the Medium: Principles of Interaction Design as a Cultural Practice. , MIT Press, ISBN: 9780262016148, November 2011.

[7] Ganandran, G. S. B., Mahlia, T. M. I., Ong, H.C., Rismanchi, B., Chong, W. T., CostBenefit Analysis and Emission Reduction of Energy Efficient Lighting at the Universiti Tenaga Nasional Scientific World Journal. 2014; 2014: 745894; https://www.ncbi.nlm.nih.gov/pmc/articles/P MC4123577/
[8] Tongji New Media Art International Center: New Media Art in large-scale exhibition Research on the "Pavilion of Footprint" of the Theme Pavilion of Expo 2010 Shanghai, Tongji University Press, 2010, P18. 